\title{
Evidence for a hyperglycaemia-dependent decrease of antithrombin III-thrombin complex formation in humans
}

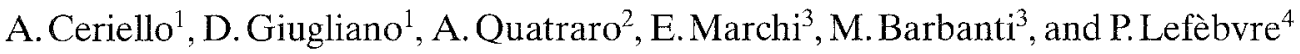 \\ Cattedra di Diabetologia e Dietoterapia, I Facoltà di Medicina, Università di Napoli, Napoli, \\ 2 Centro di Diabetologia, Casa di Cura S. Rita, Taranto, ${ }^{3}$ Alfa Ricerche, Bologna, Italy, and \\ ${ }^{4}$ Division of Diabetes, Nutrition and Metabolic Disorders, University of Liége, Liége, Belgium
}

\begin{abstract}
Summary. In the presence of increased levels of fibrinopeptide A, decreased antithrombin III biological activity, and thrombin-antithrombin III complex levels are seen in diabetic patients. Induced-hyperglycaemia in diabetic and normal subjects decreased antithrombin III activity and thrombin-antithrombin III levels, and increased fibrinopeptide A plasma levels, while antithrombin III concentration did not change; heparin was shown to reduced these phenomena. In diabetic patients, euglycaemia induced by insulin infusion restored antithrombin III activity, thrombin-anti-
\end{abstract}

thrombin III complex and fibrinopeptide A concentrations; heparin administration had the same effects. These data stress the role of a hyperglycaemia-dependent decrease of antithrombin III activity in precipitating thrombin hyperactivity in diabetes mellitus.

Key words: Antithrombin III activity, thrombin-antithrombin III complex, fibrinopeptide A, hyperglycaemia, thrombin hyperactivity.
The key event in the coagulation of blood is the conversion of prothrombin to thrombin. Once generated, this enzyme converts fibrinogen to fibrin with the release of fibrinopeptide A and B [1]. Alternatively, thrombin may be inhibited by antithrombin III (ATIII), the most relevant physiological inhibitor of this serine protease [2]. Inhibition by ATIII leads to the formation of an inactive protease-inhibitor complex [3], and this reaction is catalysed very effectively by heparin [4].

ATIII plays an important role in the control of the coagulation system, as it can inhibit the enzymes of the clotting pathway. Determination of the thrombin-antithrombin III complex (TAT) should reflect the functional state of the clotting system and represents a diagnostic tool for the detection of coagulation disorders [3]; at the same time, the measurement of fibrinopeptide A (FPA) is considered a sensitive test of in vivo thrombin formation [1].

Several studies of the fluid phase of coagulation suggest that diabetes is associated with a hypercoagulable state $[5,6]$. However, the existence of a direct link between abnormal glucose levels and the increased activity of coagulation system remains unclear [5, 6].

In this study we measured TAT, FPA and ATIII activity and concentrations, in both diabetic and normal subjects, and evaluated the effect of hyperglycaemia on these parameters.

\section{Subjects and methods}

Thirty Type 1 (insulin-dependent) diabetic subjects, selected according to the National Diabetes Data Group (NDDG) criteria [7], 15 males and 15 females (age $30 \pm 1.23$ years, mean $\pm \mathrm{SEM}$; body mass index $23.4 \pm 1.42 \mathrm{~kg} / \mathrm{m}^{2}$; duration of diabetes $8.51 \pm 1.22$ years; insulin regimen $18-70 \mathrm{IU} /$ day, mean $42.8 \pm 3.24 \mathrm{IU} /$ day) gave informed consent to this study.

Thirty healthy normal subjects, without personal or family history of diabetes, with normal glucose tolerance according to NDDG criteria [7], matched for sex (14 males and 16 females), age $\left(31 \pm 1.28\right.$ years) and body mass index $\left(22.4 \pm 1.25 \mathrm{~kg} / \mathrm{m}^{2}\right)$, served as control subjects.

All subjects consumed weight maintaining diets with at least $250 \mathrm{~g}$ carbohydrate/day for three days before the study. The women were not taking oral contraceptives. This experiment was approved by the ethical committees of our institutions.

\section{Basal study}

Plasma glucose, TAT, FPA and ATIII activity and concentrations were measured in the fasting state, in both the diabetic and normal subjects.

\section{Hyperglycaemic studies}

In five diabetic subjects (fasting glycaemia $6.5-9.0 \mathrm{mmol} / \mathrm{l}$ ), and in five normal subjects three different studies were performed in randomized order on different days. In the morning, after a 12 to $14 \mathrm{~h}$ 
Table 1. Basal fasting values in diabetic and normal subjects

\begin{tabular}{lccr}
\hline & $\begin{array}{l}\text { Diabetic } \\
\text { subjects } \\
n=30\end{array}$ & $p$-value & $\begin{array}{l}\text { Control } \\
\text { subjects } \\
n=30\end{array}$ \\
\hline $\begin{array}{l}\text { Fibrinopeptide A ng/ml } \\
\text { Thrombin-antithrombin III }\end{array}$ & $3.9 \pm 0.43$ & $<0.01$ & $1.7 \pm 0.21$ \\
$\begin{array}{l}\text { complex } \mu \mathrm{g} / \mathrm{l} \\
\begin{array}{l}\text { Antithrombin III activity \% } \\
\text { Antithrombin III }\end{array}\end{array}$ & $1.0 \pm 0.04 \pm 4.12$ & $<0.01$ & $1.9 \pm 0.07$ \\
concentration $\mu \mathrm{mol} / 1$ & $0.58 \pm 0.12$ & $\mathrm{NS}$ & $103.9 \pm 2.22$ \\
\hline
\end{tabular}

Data are reported as mean \pm SEM

fast an i.v. cannula was introduced into an antecubital vein in both arms, and kept patent with slow infusion of $0.9 \% \mathrm{NaCl}$. Venous samples for laboratory analysis were obtained from one cannula; the other cannula was used for administration of the various substances (glucose, insulin and heparin).

After the subjects had rested for $90 \mathrm{~min}$, two basal samples were obtained ( -30 and $0 \mathrm{~min}$ ), before the start of the study. In the diabetic subjects, acute elevation of glycaemia was induced with a bolus of $0.33 \mathrm{~g}$ glucose $\cdot \mathrm{kg}^{-1}$ body weight; then plasma glucose was clamped between 17 and $22 \mathrm{mmol} / 1$ for $1 \mathrm{~h}$, with bedside monitoring of the plasma glucose concentration which served to adjust the rate of a $50 \%$ glucose infusion.

In the normal subjects, hyperglycaemia was induced according to the method of Cerasi and Luft [8]. Each subject received a bolus of $0.5 \mathrm{~g}$ glucose $\cdot \mathrm{kg}^{-1}$ body weight in less than $2 \mathrm{~min}$; glucose $\left(20 \mathrm{mg} \cdot \mathrm{kg}^{-1} \cdot \mathrm{min}^{-1}\right.$ ) was then infused via a peristaltic pump for $1 \mathrm{~h}$. Blood samples were collected every $10 \mathrm{~min}$ in the first $\mathrm{h}$ and at 90 , 120 and $180 \mathrm{~min}$. As in the control study, each subject received an equivalent infusion of an isovolumic-isotonic $\mathrm{NaCl}$ solution.

The studies described above were repeated in both the normal and diabetic subjects, with the sole exception that heparin (5000 U as i. v. bolus, followed by an i.v. infusion at the rate of $750 \mathrm{U} / \mathrm{h}$ ) accompanied the hyperglycaemic clamp.

\section{Normoglycaemic studies}

In five diabetic subjects (fasting glycaemia 14.2-17 mmol/1), after a $30 \mathrm{~min}$ baseline period, normoglycaemia was achieved with a $1 \mathrm{mU} \cdot \mathrm{kg}^{-1} \cdot \mathrm{min}^{-1}$ insulin infusion for $2 \mathrm{~h}$. Samples were obtained at $-30,0,30,60,70,80,90,100,110,120$ and $180 \mathrm{~min}$.

\section{Heparin studies}

After a $30 \mathrm{~min}$ baseline period i.v. heparin (5000 $\mathrm{U}$ as a bolus plus $750 \mathrm{U} / \mathrm{h}$ ) was infused for $1 \mathrm{~h}$ in five diabetic subjects; blood samples were obtained at $-30,0$ and every $10 \mathrm{~min}$ in the first $\mathrm{h}$, and at 90,120 and $180 \mathrm{~min}$.

\section{Analytical methods}

Venous blood was drawn in plastic syringes containing $3.8 \%$ sodium citrate 9:1 volume/volume). Subsequently, samples were centrifuged for $15 \mathrm{~min}$ at $2000 \times \mathrm{g}$ at $4^{\circ} \mathrm{C}$ and the plasma obtained was used to test glycaemia, TAT levels, ATIII activity and concentration. Plasma glucose was measured by the glucose-oxidase method. ATIII biological activity was measured according to Abildgaard [9]. ATIII concentration was evaluated by radial immunodiffusion, according to Mancini [10].

TAT concentrations were quantitated by a solid phase ELISA, according to Pelzer [11], with the commercially available kit from Behringwerke AG (Marburg, FRG).
FPA estimation was performed by RIA, using a commercially abtained kit (Mallinkrodt, St. Louis, Mo., USA). Samples were drawn directly into a vacutainer containing the anticoagulant diluent supplied with the kit.

For each time point of the study the ratio of the mean basal period haematocrit to the observed haematocrit was used to correct the dilutional error introduced by blood volume expansion.

\section{Statistical analysis}

Statistical significance was determined by the analysis of variance. Data are reported as mean $\pm \mathrm{SEM}$.

\section{Results}

\section{Basal study}

ATIII functional activity and TAT concentrations were significantly reduced in the diabetic patients (Table 1 $p<0.01$ ). FPA levels were increased in diabetic subjects, while the ATIII concentration was not different between the diabetic and control subjects (Table 1).

\section{Hyperglycaemic studies}

All subjects, both diabetic and normal, had sustained elevation of plasma glucose levels, as the result of glucose infusion. No difference between mean glycaemic incremental areas (from 0 to $120 \mathrm{~min}$ ) existed in the two experiments (with or without heparin) in the two groups of normal $(13.5 \pm 1.2 \mathrm{vs} 13.6 \pm 1.3 \mathrm{mmol} / \mathrm{l})$ or diabetic $(11.6 \pm 1.4 \mathrm{vs} 11.4 \pm 1.3 \mathrm{mmol} / \mathrm{l})$ subjects.

Basal plasma glucose levels, TAT, FPA, ATIII activity and concentrations were similar before the hyperglycaemic studies (with or without heparin) in each group of normal and diabetic subjects (Fig.1). A significant decrease in both ATIII activity and TAT concentrations, and an increase of FPA occurred during hyperglycaemia in both of the groups $(0-120 \mathrm{~min} ; p<0.01)$, while the ATIII concentration was unchanged (Fig. 1).

Heparin preserved ATIII activity and the TAT decrease, FPA showed a minor increase, while ATIII concentration was not affected (Fig.1). The isovolumic-isotonic infusion produced only a slight and insignificant rise in FPA concentration (Fig. 1).

\section{Normoglycaemic studies}

Insulin-induced euglycaemia in diabetic patients increased both the ATIII activity and TAT concentrations, and decreased FPA concentrations (Fig. 2).

\section{Heparin studies}

The infusion of heparin in the diabetic subjects ameliorated ATIII activity and TAT plasma levels, decreased FPA concentration, while it did not affect the ATIII concentration (Fig. 3). 

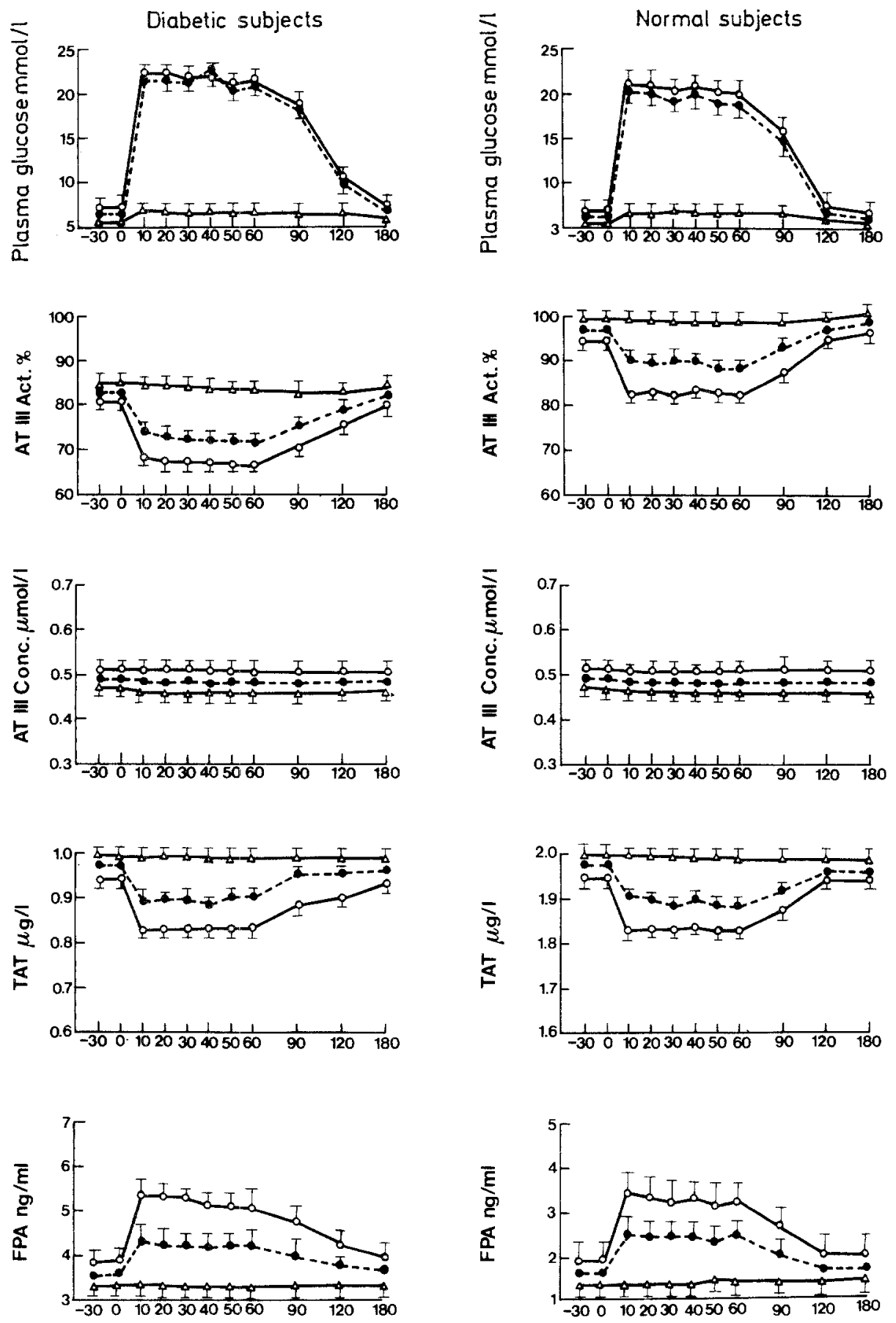

Fig.1. Effect of inducedhyperglycaemia on diabetic and normal subjects. O-O glucose, $-\cdots \cdot$ glucose plus heparin, $\Delta-\Delta$ control. ATIII = antithrombin III, $\mathrm{TAT}=$ thrombin-antithrombin III complex, FPA = fibrinopeptide A

Minutes

\section{Discussion}

In this study the presence in diabetes of an increased FPA concentration and decreased levels of TAT and ATIII activity, despite normal plasma concentrations, has been demonstrated.

The discrepancy between TAT and FPA levels in diabetes seems, apparently, surprising since both are considered a good index of hypercoagulability. Decreased ATIII activity, in the presence of its normal plasma concentration [12], and increased FPA levels [13] have already been demonstrated in diabetes, as well as the direct role of hyperglycaemia in conditioning these phenomena both in diabetic $[13,14]$ and normal $[15,16]$ subjects. The FPA hyperglycaemia-mediated increase revealed the presence of a hyperglycaemia-dependent thrombin hyperactivation, however, a role for decreased ATIII activity in conditioning this phenomenon was hypothesized [5].

The presence of decreased TAT levels, correlated to ATIII decreased activity and FPA increase in diabetes, strengthens this hypothesis. The possibility of reproducing this situation during induced hyperglycaemia in healthy subjects, furthermore, shows that this phenomenon is clearly hyperglycaemia-dependent. 

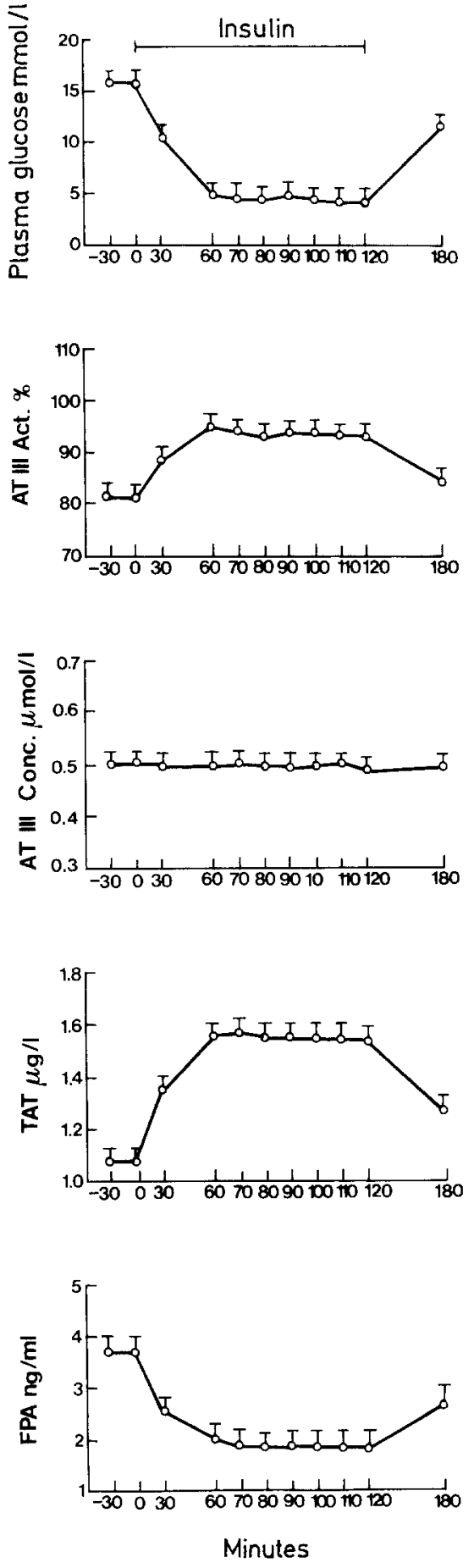

Fig. 2. Effect of normoglycaemia on diabetic patients. ATIII = antithrombin III, TAT $=$ thrombin-antithrombin III complex, FPA = fibrinopeptide A

FPA levels and ATIII activity may be restored by heparin administration $[13,15,17]$. In this study heparin shows the ability to increase TAT levels, simultaneously increasing ATIII activity and decreasing the FPA concentration. This effect confirms that the level of ATIII activity plays an important role in conditioning hyperglycaemiainduced thrombin hyperactivity.

Our data suggest that the hyperglycaemia-related thrombin hyperactivation seems, very likely to be linked
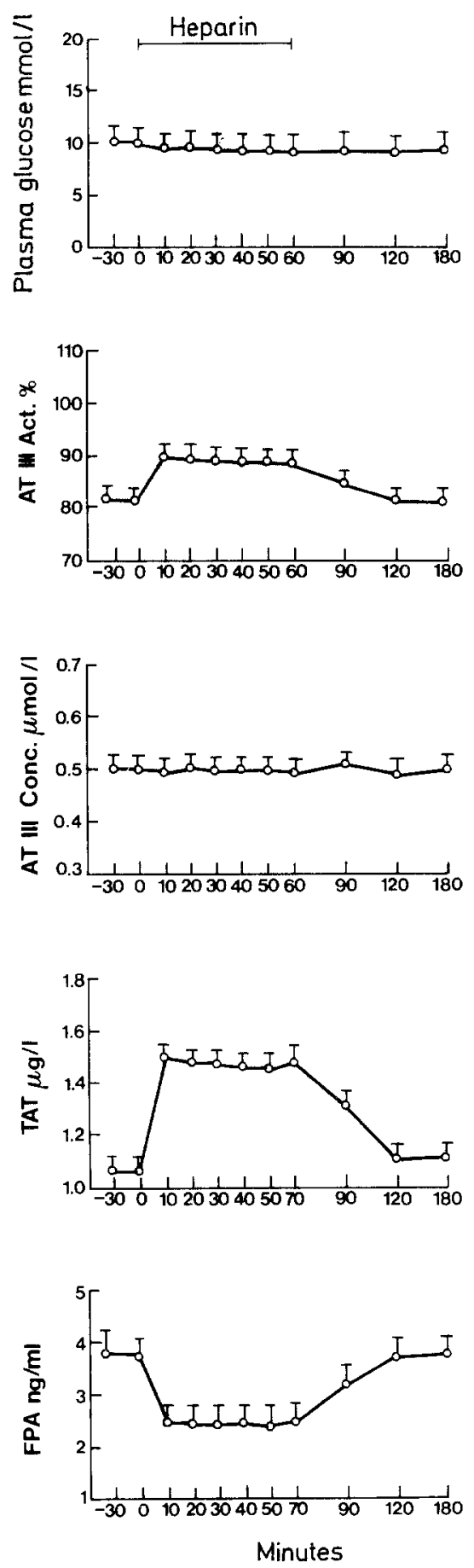

Fig.3. Effect of heparin administration on diabetic patients. ATIII = antithrombin III, TAT $=$ thrombin-antithrombin III complex, FPA = fibrinopeptide $\mathrm{A}$

to a hyperglycaemia-induced decrease of ATIII activity. The decrease of ATIII biological activity conditions a minor antithrombin effect of ATIII, as demonstrated by the reduced TAT levels. The reduced inhibition of thrombin may produce a relative hyperactivity of this enzyme, precipitating an increase in FPA.

The relevance of this study is the demonstration that the hyperglycaemia-induced decrease of ATIII activity may precipitate a decrement of TAT formation that per- 
mits a thrombin hyperactivity, as demonstrated by the FPA increase. Thus, the hyperglycaemia-induced ATIII alterations seem to play a central role in the development of coagulation alterations in diabetes.

\section{References}

1. Nossel HL, Yudelman J, Canfield RE, Butler VP, Spanondis K, Wilner GD, Qureshi GD (1974) Measurement of Fibrinopeptide A in human blood. J Clin Invest 54: 43-53

2. Rosemberg RD, Damus PS (1973) The purification and mechanism of human antithrombin-heparin cofactor. J Biol Chem 248: 6490-6505

3. Owen WG (1975) Evidence for the formation of an ester between thrombin and heparin cofactor. Biochim Biophys Acta 450: $380-387$

4. Griffith MJ (1982) Kinetics of the heparin-enhanced antithrombin III/thrombin reaction. J Biol Chem 257: 7360-7365

5. Jones RL, Peterson CH (1981) The fluid phase of coagulation and the accelerated atherosclerosis of diabetes mellitus. Diabetes 30 [Suppl.2]: 33-38

6. Ostermann $\mathrm{H}$, van de Loo $\mathrm{J}$ (1986) Factors of the hemostatic system in diabetic patients. A survey of controlled study. Haemostasis 16: $386-416$

7. National Diabetes Data Group (1979) Classification and diagnosis of diabetes mellitus and other categories of glucose intolerance. Diabetes 28: 1039-1057

8. Cerasi E, Luft R (1967) "What is inherited - what is added?" hypothesis for the pathogenesis of diabetes mellitus. Diabetes 16: $615-627$

9. Abildgaard U, Lie M, Odegard OR (1977) Antithrombin III (heparin co-factor) assay with "new" chromogenic substrates (S-2238 and Chromozym TH). Thromb Res 11: 549-554

10. Mancini $G$, Carbonara AO, Heremans JF (1965) Immunochemical quantitation of antigens by single radial immunodiffusion. Immunochemistry 2: 235-242
11. Pelzer H, Schwarz A, Heimburger N (1988) Determination of human thrombin-antithrombin III complex in plasma with enzyme-linked immunosorbent assay. Thromb Haemostas 59: 101-106

12. Ceriello A, Dello Russo P, Zuccotti C, Florio A, Nazzaro S, Pietrantuono C, Rosato GB (1983) Decreased antithrombin III activity in diabetes may be due to non-enzymatic glycosylation. A preliminary report. Thromb Haemostas 50: 633-634

13. Jones RL (1985) Fibrinopeptide A in diabetes mellitus: relation to levels of blood glucose, fibrinogen disappearance, and hemodynamic changes. Diabetes 34: 836-843

14. Ceriello A, Giugliano D, Quatraro A, Stante A, Consoli G, Dello Russo P, D'Onofrio F (1987) Daily rapid blood glucose variations may condition antithrombin III biologic activity but not its plasma concentration in insulin-dependent diabetes. A possible role for labile non-enzymatic glycation. Diab Metabol 13: 16-19

15. Ceriello A, Giugliano D, Quatraro A, Stante A, Consoli G, Dello Russo P, D'Onofrio F (1987) Induced-hyperglycemia alters antithrombin III activity but not its plasma concentration in healthy normal subjects. Diabetes 36: 320-323

16. Ceriello A, Giugliano D, Quatraro A, Dello Russo P, Marchi E, Torella R (1989) Hyperglycemia may determine fibrinopeptide A plasma level increase in humans. Metabolism (in press)

17. Ceriello A, Giugliano D, Quatraro A, Stante A, Consoli G, Dello Russo P, D'Onofrio F (1986) Heparin preserves antithrombin III biological activity from hyperglycemia-induced alterations in insulin-dependent diabetics. Haemostasis 16: 458-464

Received: 24 July 1989

and in revised form: 16 October 1989

Dr. A. Ceriello

Viale Lincoln 4

Parco Mecos

I-81100 Caserta

Italy 